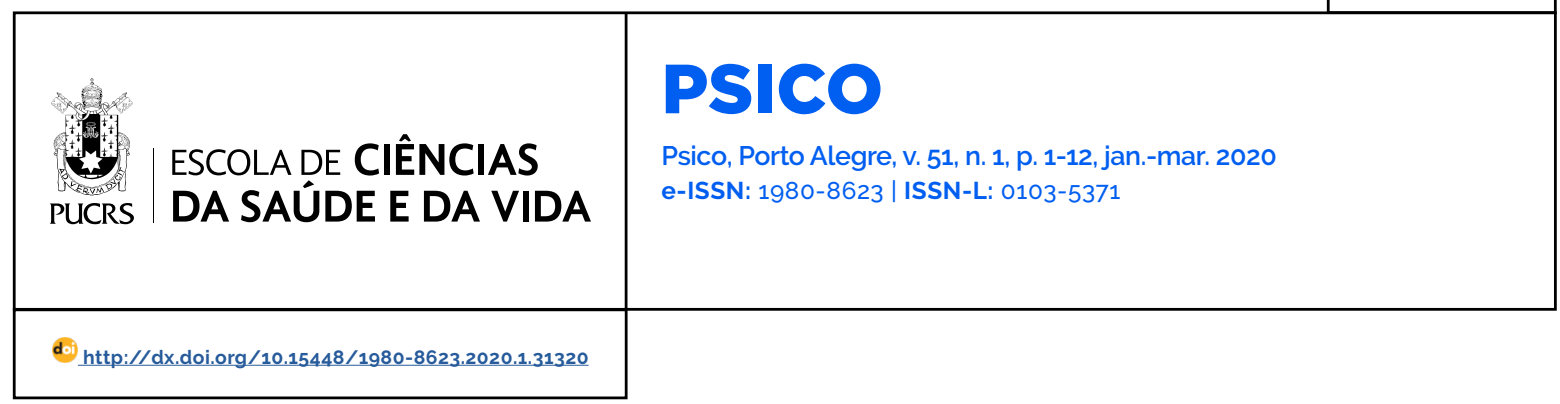

ARTIGOS

\title{
"Não tem nada para fazer lá": trabalho e pessoas com deficiência visual
}

\author{
"There is nothing to do there": work and people with visual impairment \\ "No tiene nada que hacer alli": trabajo y personas con deficiência visual
}

\section{Leonardo de Oliveira \\ Barros $^{1}$}

orcid.org/0000-0002-8406-0515

leonardobarros lob@hotmail.com

\section{Rodolfo Augusto \\ Matteo Ambiel ${ }^{1}$}

orcid.org/0000-0002-3921-8547 rodolfo.ambiel@usf.edu.br

Recebido em: 4 jul. 2018 Aprovado em: 10 set. 2019. Publicado em: $x x$ xxx. 2020.

\section{(c) (i)}

Artigo está licenciado sob forma de uma licença Creative Commons Atribuição 4.0 Internacional.
Resumo: O objetivo foi verificar a percepção de satisfação no trabalho, motivos de insatisfação e barreiras para inserção laboral de pessoas com deficiência visual. Participaram 136 pessoas com deficiência visual, com baixa visão e cegueira congênita ou adquirida, com idade média de 37,86 ( $D P=14,39$ ), sendo $52,2 \%$ do sexo feminino. Os participantes responderam ao questionário de identificação e três perguntas sobre satisfação, insatisfação e dificuldades percebidas para inserção laboral. Os dados foram analisados qualitativamente por meio de análise de conteúdo e quantitativamente com estatísticas inferenciais. Os resultados indicaram que os motivos de mais insatisfações foram relativos a conflitos organizacionais e falta de acessibilidade. Em relação às barreiras para inclusão, identificou-se o preconceito e o desconhecimento social sobre a deficiência como aspectos de maior limitação. Além disso, na comparação por tipo de deficiência, as maiores dificuldades foram para pessoas com cegueira congênita.

Palavras-chave: inclusão social, satisfação no trabalho, deficiente visual.

Abstract: The objective was to verify the perception of job satisfaction, reasons for dissatisfaction, and barriers to job insertion of people with visual impairment. Participants were 136 people with visual impairment, low vision, and congenital or acquired blindness, with a mean age of 37.86 (SD =14.39), 52.2\% being female. Participants answered the identification questionnaire and three questions about satisfaction, dissatisfaction, and perceived difficulties for job insertion. Data were qualitatively analyzed through content analysis and quantitatively with inferential statistics. The results indicated that the reasons for greater dissatisfaction were related to organizational conflicts and lack of accessibility. Regarding barriers to inclusion, prejudice, and social ignorance about disability were identified as aspects of more significant limitation. Moreover, when comparing by type of disability, the greatest dissatisfactions and difficulties were for people with congenital blindness.

Keywords: social inclusion, job satisfaction, visualy disabled.

Resumen: El objetivo fue verificar la percepción de satisfacción laboral, los motivos de insatisfacción y las barreras para la inserción laboral de personas con discapacidad visual. 136 personas con discapacidad visual, baja visión y ceguera congénita o adquirida, con una edad media de 37.86 ( $D E=14.39$ ), 52.2\% mujeres, participaron en este estudio. Los participantes respondieron el cuestionario de identificación y tres preguntas sobre satisfacción, insatisfacción y dificultades percibidas para la inserción laboral. Los datos se analizaron cualitativamente a través del análisis de contenido y cuantitativamente con estadisticas inferenciales. Los resultados indicaron que las razones para una mayor insatisfacción estaban relacionadas con los conflictos organizacionales y la falta de accesibilidad. Con respecto a las barreras a la inclusión, los prejuicios y la ignorancia social sobre la discapacidad se identificaron como aspectos de mayor limitación. Además, al comparar por tipo de discapacidad, las mayores dificultades fueron para las personas con ceguera congénita.

Palabras clave: inclusion social, satisfacción en el trabajo, discapacidad visual. 
A inclusão de pessoas com deficiência no mercado de trabalho tem sido assunto recorrente nos últimos anos. Em termos de garantias legais, a Lei Brasileira de Inclusão da Pessoa com Deficiência ou Estatuto da Pessoa com Deficiência (Lei n. ${ }^{\circ}$ 13.146/2015), marco na luta por igualdade, assegura que independentemente do tipo de deficiência, a pessoa tem direito ao trabalho de sua livre escolha e aceitação, com igualdade de oportunidades entre os individuos com e sem deficiência. O Estatuto reafirma outras legislações e convenções das quais o País é signatário, tais como a "Lei de Cotas" (art. 93 da Lei n. ${ }^{\circ}$ 8213/1991) e a Convenção Internacional sobre os Direitos das Pessoas com Deficiência (Decreto n. ${ }^{\circ}$ 6.949/2009) e reforça a importância da acessibilidade nos espaços laborais, tanto em termos ambientais como do uso de equipamentos de tecnologia assistiva. É direito, também, a participação em serviços de formação, educação continuada, remuneração de igual valor e o acesso a políticas públicas que garantam a sua inserção e permanência laboral.

As determinações legais visam colaborar para o fim da segregação social da pessoa com deficiência e, especificamente, em relação à organização tradicional do trabalho, romper com o padrão normativo no qual não há espaço para a diferença (Ribeiro \& Ribeiro, 2012; Ribeiro \& Ribeiro, 2008). Todavia, apesar da possibilidade de entrada de pessoas com deficiência no mercado de trabalho, quando essa ocorre, nem sempre há inclusão efetiva, pois, em algumas culturas organizacionais embora a pessoa com deficiência atinja o papel de trabalhador, não há uma percepção de igualdade em relação aos funcionários sem deficiência (Dipboye \& Colella, 2005). Nesta lógica, duas posições são possiveis para as pessoas com deficiência no mundo do trabalho, quais sejam: a de negação da própria deficiência enquanto possibilidade de existência e a posição de tutelado que despotencializa o individuo e reafirma o assistencialismo como método mais adequado (Ribeiro \& Ribeiro, 2008).

Na percepção das pessoas com deficiência os maiores entraves para inserção e permanência no trabalho decorrem da falta de acessibilidade nos espaços e equipamentos, bem como, da superproteção familiar e dos colegas em relação às suas habilidades e do preconceito da sociedade para às pessoas com deficiência e da própria pessoa em relação a ela mesma (Pinheiro \& Dellatorre, 2015). Tais aspectos afetam o nivel de satisfação no trabalho, sendo que além das variáveis citadas, a satisfação tende a diminuir em situações nas quais a pessoa com deficiência atua em cargos diferentes da sua área de formação ou em ocupações que não permitam o desenvolvimento e expressão da criatividade, da independência e da autonomia (Assunção, Carvalho-Freitas, \& Oliveira, 2015).

Outros fatores sociais também dificultam a inclusão laboral de pessoas com deficiência. Em termos atitudinais, os empregadores tendem a realizar a contratação apenas por exigência da Lei, optando por pessoas com deficiências que não demandam de muitas adaptações na empresa ou que possam ocupar funções que seriam insalubres para pessoas sem deficiência, como por exemplo, a contratação de pessoas com deficiência auditiva para linhas de produção (Lima, Silva, \& Galvão, 2010; Toldrá, 2009; Veltrone \& Almeida, 2010; Violante \& Leite, 2011). A principal justificativa dos gestores para a não contratação de pessoas com deficiência é a da baixa escolarização e a capacitação profissional desse púbico, fator que diminui o ganho salarial e a efetivação nas empresas (Ribeiro, Batista, Prado, Vieira, \& Carvalho, 2014). Neste sentido, percebe-se que há exclusão de pessoas com deficiência também nos campos da educação e da qualificação profissional.

No Brasil, de acordo com o último censo demográfico, há 45.5 milhões de pessoas autodeclaradas com alguma deficiência, sendo que a maior prevalência é de pessoas com deficiência visual, atingindo 35,7 milhões (18,8\% da população) (Instituto Brasileiro de Geografia e Estatística [IBGE], 2011). Os dados do censo indicaram que a deficiência visual atinge mais mulheres do que homens, com maior concentração no grupo etário de 65 anos ou mais 
$(49,8 \%)$ e na região Nordeste (26,6\%). Em relação ao campo laboral, a inserção de mulheres com deficiência visual no mercado de trabalho foi inferior aos homens. De modo geral, as diferenças de sexo superaram a existência da própria deficiência como fator limitante para o acesso ao trabalho, sendo que o nivel de ocupação da população masculina com pelo menos uma das deficiências foi de 57,3\%, e da feminina de 37,8\%.

Sobre o rendimento financeiro de pessoas com deficiência visual, verificou-se que a maior parte recebia entre 1 e 2 salários mínimos (29\%), seguidos daqueles que recebiam de meio a 1 salário $(26,2 \%)$ e meio salário (10,6\%). As classes mais altas (acima de 30 salários) reuniram 0,3\% dos deficientes visuais e $9.5 \%$ declararam não ter nenhuma espécie de rendimento (IBGE, 2010). O baixo rendimento financeiro de pessoas com deficiência pode ser relacionado com a limitada participação da população no mercado de trabalho, bem como, baixa escolarização, qualificação e não desenvolvimento de habilidades profissionais. Associa-se a tal aspecto uma maior instabilidade profissional, baixa experiência laboral adquirida com a idade e a discriminação contra esse público, que mesmo com experiência profissional encontra dificuldades de ascensão no mercado de trabalho (Garcia \& Maia, 2014).

As atitudes dos empregadores e colegas de trabalho tendem a influenciar na manutenção do trabalhador com deficiência visual em suas ocupações. Conforme relatado por Andrade, Silva e Veloso (2017) e Bacelo (2012), trabalhadores cegos sentem a necessidade de um esforço extra para provar que merecem a oportunidade de exercer uma atividade laboral, demonstrando as falhas no processo de integração nas organizações. Assim, o desenvolvimento de um clima organizacional adequado, pode melhorar o grau das relações, o envolvimento das pessoas com deficiência com o seu trabalho e facilitar a adaptação, vinculação e satisfação (Hashim, Ishak, \& Hilmi, 2017).

Frente ao exposto, torna-se importante avançar nas discussões sobre a inclusão de pessoas com deficiência no mercado de trabalho (Ribeiro et al., 2014). Assim, considerando o alto número de pessoas com deficiência visual no Brasil (IBGE, 2011), esta pesquisa de cunho qualitativo e quantitativo, teve por objetivo verificar a percepção de satisfação no trabalho, motivos de insatisfação e barreiras para inserção da pessoa com deficiência visual no campo laboral. Além disso, buscou-se identificar possiveis diferenças em função do sexo, tipo de deficiência e nivel de escolaridade.

\section{Método}

\section{Participantes}

Participaram 136 pessoas com deficiência visual, com idades entre 18 e 76 anos $(M=$ $37,86, \mathrm{DP}=14,39)$, sendo $52,2 \% \quad(n=71)$ do sexo feminino. No tocante ao tipo de deficiência, $27,2 \%$ ( $n=37)$ declarou ter baixa visão congênita, $23.5 \%(n=32)$ baixa visão adquirida, 16.9\% ( $n=23)$ cegueira congênita e 32,4\% ( $n=44)$ cegueira adquirida. Os participantes foram oriundos de todas as regiões do Brasil com respondentes em 15 estados e com maior concentração no estado de São Paulo ( $n=101,73,7 \%$ ). Em relação ao nivel de escolaridade, 7,4\% ( $n=10)$ declarou não ter concluido o Ensino Fundamental, 14,7\% $(\mathrm{n}=20)$ afirmou ter realizado apenas o Ensino Fundamental, 48,5\% ( $n=66)$ concluiu o Ensino Médio ( $n=66), 17,6 \%(n=24)$ alegou ter concluido Ensino Superior e 11,8\% ( $n=16)$ informou ter PósGraduação ( $n=16)$. Sobre a situação laboral, 40,4\% ( $n=55)$ dos participantes encontravam-se ativos no mercado de trabalho, 40,4\% $(n=55)$ não trabalhavam e 19,1\% ( $n=26$ ) estavam aposentados por tempo de serviço, invalidez ou recebendo o Benefício de Prestação Continuada. Trata-se de uma amostra de conveniência.

\section{Instrumentos}

Questionário de inclusão laboral (desenvolvido pelos autores), contendo perguntas de caracterização sociodemográficas e as seguintes questões: (a) Você está satisfeito no ambiente de trabalho?; (b) O que te deixa mais insatisfeito no ambiente de trabalho?; e (c) Em sua opinião, qual o maior impedimento para que a pessoa com deficiência visual consiga trabalhar? Com exceção da primeira questão respondida de forma 
dicotômica (sim ou não), as demais eram abertas e sem limites de caracteres para os respondentes.

\section{Procedimentos}

A pesquisa faz parte de um projeto mais amplo que foi. Foi autorizado pelo Comitê de Ética em Pesquisas da Universidade São Francisco (CAAE: 49153715.2.0000.5514). Para responderem a pesquisa os participantes deveriam ter idade a partir de 18 anos e concordar com o Termo de Consentimento Livre e Esclarecido. A coleta de dados ocorreu entre os meses de abril e junho de 2016 na modalidade presencial, em locais prédefinidos,e informatizada, por meio de elaboração do protocolo de pesquisa na plataforma Google Forms. A recolha dos dados na modalidade presencial aconteceu em dias previamente agendados, em seis (6) instituições de apoio à pessoa com deficiência visual do estado de São Paulo. Para aplicação presencial, o aplicador fez a leitura das perguntas e registrou as respostas dos participantes levando aproximadamente 10 minutos por pessoa. Para a coleta informatizada, houve a divulgação do link de acesso ao protocolo em páginas e grupos específicos de pessoas com deficiência visual em redes sociais online. Do total de pessoas que participaram da pesquisa, 40,9\% ( $n=56)$ responderam aos instrumentos por meio de aplicação presencial. Contudo, a maior parte da amostra realizou a pesquisa de forma autônoma utilizando computador ( $n=58,43,1 \%$ ), aparelho celular $(n=20,14,6 \%)$ e tablet $(n=2,1,5 \%)$.

\section{Análise de dados}

Inicialmente os dados foram organizados por meio do software Statistical Package for the Social Sciences (SPSS) versão 21, tendo sido realizadas análises descritivas para a caracterização da amostra. Em seguida, foram empregadas análises de conteúdo para as perguntas abertas do questionário, sendo que para verificar frequência das palavras utilizou-se o site WordArt (https:// wordart.com recuperado em 10 de junho de 2018) para gerar as nuvens de palavras. Posteriormente, com o intuito de formar categorias de respostas foram empregados os passos propostos por Moraes
(1999) ao sintetizar os procedimentos de análise de conteúdo. Neste sentido, ocorreu a preparação das informações, a transformação do conteúdo em unidades, a classificação das unidades em categorias, a descrição e a interpretação.

Para a pergunta sobre a insatisfação no trabalho, as oito categorias definidas foram: salário, atuar em outra área, falta de acessibilidade, conflitos organizacionais, preconceito, nenhuma insatisfação, não ter função real no trabalho e não gostar o trabalho. Para a pergunta "Em sua opinião, qual o maior impedimento para que a pessoa com deficiência visual consiga trabalhar?", foram geradas 11 categorias de respostas, a saber: preconceito, superproteção familiar, falta de acesso à educação, não existem impedimentos, falta de acessibilidade na cidade ou na empresa, falta de aceitação própria, medo de perder o benefício, falta de aplicação da Lei de Cotas, ausência de vagas ou oportunidades, a deficiência, e desconhecimento sobre a deficiência.

Por fim, empregaram-se análises estatísticas para comparação das médias dos participantes em relação às variáveis sexo, escolaridade e tipo de deficiência. Utilizou-se teste $t$ de Student, Análise de variância (ANOVA) e Prova de Tukey com o intuito de verificar diferenças estatisticamente significativas entre os grupos.

\section{Resultados}

Inicialmente buscou-se analisar entre as pessoas que trabalhavam qual o grau de satisfação com o trabalho. Dos 55 participantes que estavam laboralmente ativos, 39 (70,9\%) declararam estar satisfeitos, $13(23,6 \%)$ insatisfeitos e 3 pessoas (5.5\%) não responderam a essa questão. Na sequência, foram analisadas as frequências das palavras para a pergunta "o que te deixa mais insatisfeito no ambiente de trabalho". A pergunta foi aberta e sem limite de caracteres para a resposta. Cabe ressaltar que só responderam essa questão as pessoas que declararam trabalhar $(n=55)$. Ao analisar o conteúdo das afirmativas, gerou-se a nuvem de palavras apresentada na Figura 1. 


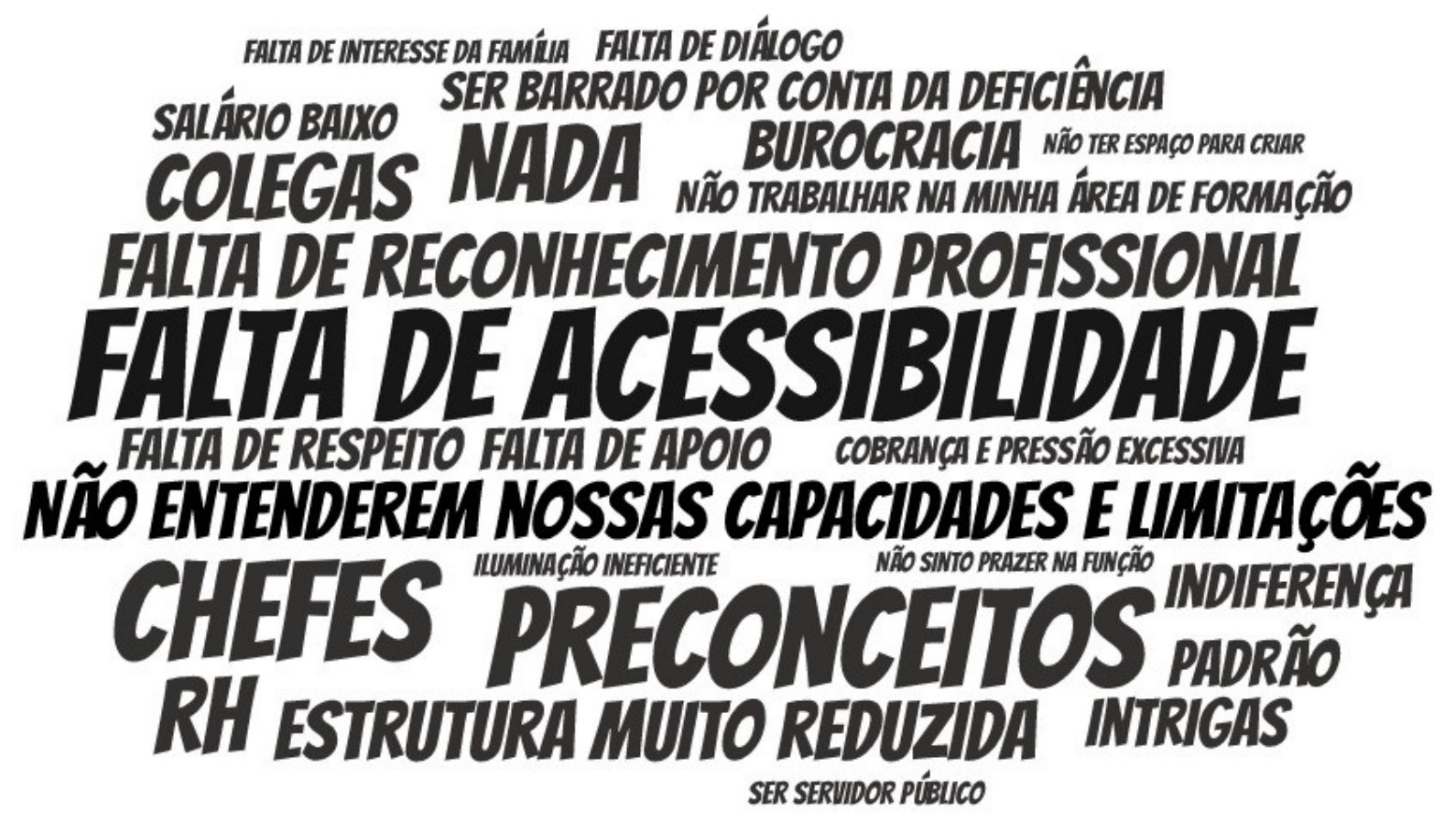

Figura 1 - Nuvem de palavras para motivos de insatisfação no trabalho

Verifica-se que a falta de acessibilidade no ambiente de trabalho apresentou-se como o principal motivo de insatisfação no trabalho, seguido do preconceito e da falta de reconhecimento profissional. Em menor frequência apareceram respostas como a ausência de prazer na função e salário. Após o procedimento de nuvem de palavras foram verificadas a frequências de respostas das categorias geradas para a questão de insatisfação no trabalho. Os resultados são expostos na Tabela 1.

TABELA 1 - Frequência das respostas relacionadas aos motivos de insatisfação no trabalho

\begin{tabular}{|c|c|c|}
\hline Categoria & $\mathbf{F}$ & Exemplos de discurso \\
\hline Conflitos organizacionais & 17 & $\begin{array}{l}\text { "Falta de respaldo dos superiores" "Intrigas" "Falta de reconhecimento pro- } \\
\text { fissional" "Falta um plano de carreira estruturado" }\end{array}$ \\
\hline Falta de acessibilidade & 11 & $\begin{array}{c}\text { "Acessibilidade e iluminação ineficiente" "Falta de recursos tecnológicos e } \\
\text { equipamentos acessiveis" "Falta de investimento acessibilidade" "Ter que } \\
\text { depender dos outros para me locomover" }\end{array}$ \\
\hline Nenhuma insatisfação & 7 & "Nada" \\
\hline Atuar em outra área & 3 & $\begin{array}{c}\text { "Trabalho fora da minha área de estudos" "Este emprego é temporário e } \\
\text { está fora da minha área de formação" }\end{array}$ \\
\hline Preconceito & 3 & $\begin{array}{c}\text { "Preconceito existente na empresa por parte de alguns colegas" "A forma } \\
\text { das pessoas não entenderem como a gente enxerga" }\end{array}$ \\
\hline Salário & 2 & "O salário baixo" "Salário incompativel com minha formação" \\
\hline $\begin{array}{l}\text { Não ter função real no } \\
\text { trabalho }\end{array}$ & 2 & "Não tem nada para eu fazer lá" \\
\hline Não gostar do trabalho & 1 & "Não sinto prazer na função que exerço" \\
\hline
\end{tabular}


Observa-se que as maiores frequências foram relativas à conflitos no espaço de trabalho, envolvendo questões como dificuldades de relacionamento interpessoais, ausência de um plano de carreira, bem como, muitas queixas da falta acessibilidade que acaba prejudicando o desempenho das atividades e não estimulando a autonomia da pessoa no ambiente de trabalho. Na sequência, por meio da nuvem de palavras, foram analisadas as respostas para a questão de principais impedimentos para que a pessoa com deficiência visual consiga trabalhar e os resultados são apresentados na Figura 2. Nesta análise, considerou-se a amostra total.

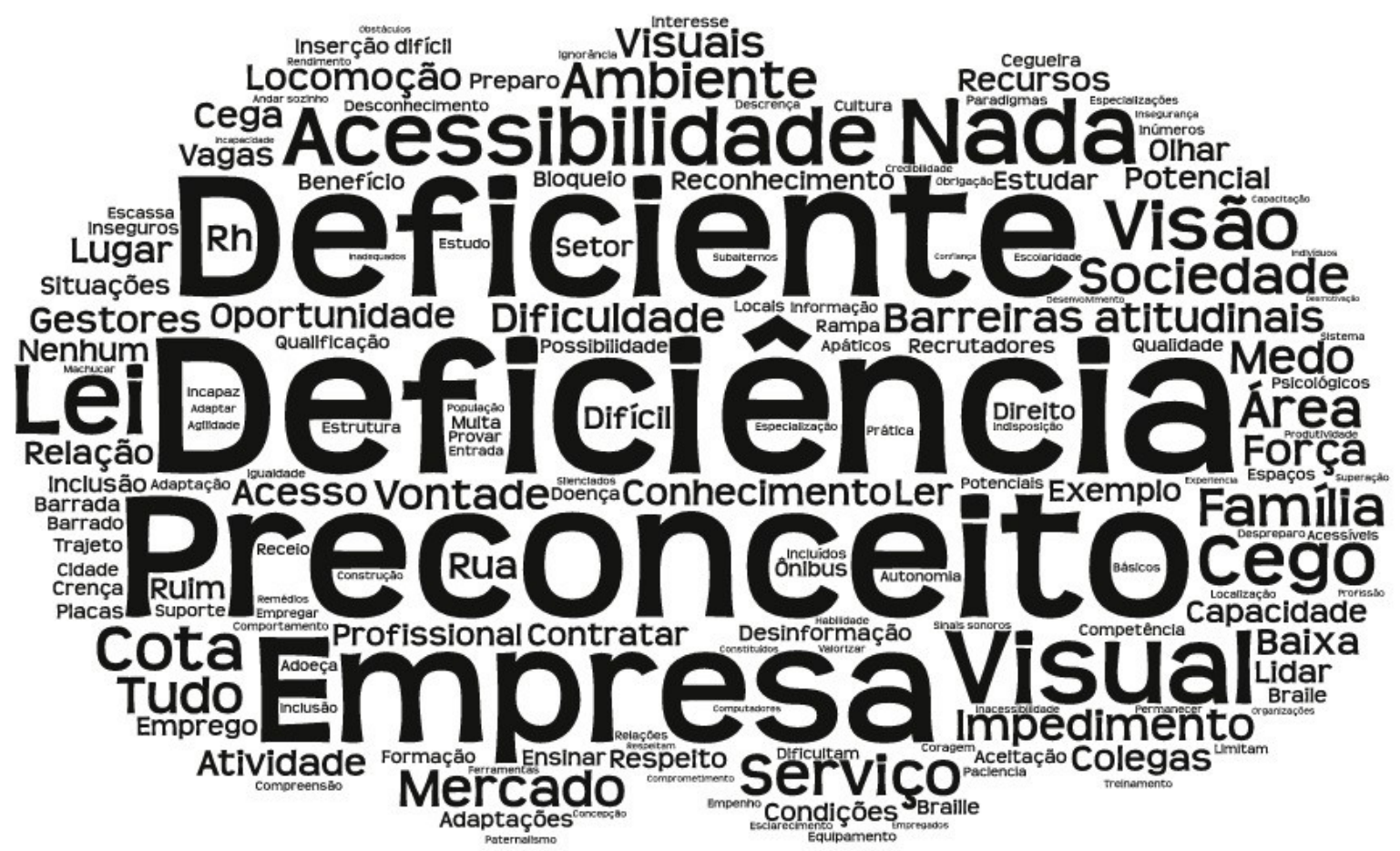

Figura 2 - Nuvem de palavras para principais dificuldades de inserção no mercado de trabalho

Percebe-se que a própria deficiência ou ser deficiente foi identificado como o maior impedimento para inserção laboral. Em seguida, o preconceito foi citado como um dos dificultadores tanto em relação à deficiência como por barreiras atitudinais por parte das empresas e contratantes. A partir da análise de conteúdo, efetuou-se a frequência das respostas para as principais dificuldades identificadas para inserção laboral. Os resultados são apresentados na Tabela 2.

TABELA 2 - Frequência das respostas acerca das dificuldades de inserção laboral

\begin{tabular}{|c|c|c|}
\hline Categoria & $\mathbf{F}$ & Exemplos de discurso \\
\hline Preconceito & 50 & $\begin{array}{c}\text { "Preconceito, acham que a gente não serve para nada" "Depende da atividade e } \\
\text { da empresa, era barrada por preconceito dos gestores que não sabem o que uma } \\
\text { pessoa com deficiência visual pode fazer." }\end{array}$ \\
\hline $\begin{array}{l}\text { Desconhecimento } \\
\text { social sobre a defici- } \\
\text { ência }\end{array}$ & 45 & $\begin{array}{c}\text { "Acham que a gente não serve para nada" "A falta de credibilidade da sociedade em } \\
\text { relação à pessoa com deficiência" }\end{array}$ \\
\hline
\end{tabular}


Falta de acessibilidade na cidade e na empresa

A deficiência

Nenhum impedimento

Falta de acesso à educação

Ausência de vagas ou oportunidades

Falta de aceitação própria

Ineficiência da Lei de Cotas

Superproteção familiar

Medo de perder o beneficio
"Falta de oportunidade" "Falta de oportunidade por parte dos empregadores" "As empresas não dão oportunidades porque acham que não terão rendimento com individuos com deficiência" "Receio dos empregadores de contratar a gente"

"A descrença da pessoa em seus próprios potenciais" "Desmotivação do deficiente visual" "A insegurança do deficiente visual também para enfrentar as situações de impedimentos e mostrar suas capacidades." "A concepção de incapacidade que a própria pessoa com deficiência ainda traz dentro de si"

"Geralmente as empresas querem deficientes físicos, dificilmente querem ou aceitam deficientes visuais, principalmente com cegueira total" "Em diversas vezes, muitas empresas não querem contratar deficientes visuais totais pela questão de não terem conhecimento a respeito de como os deficientes visuais trabalham, de suas ferramentas, adaptações ou produtividade." "Acredito que ainda hoje, após 20 anos da Lei de Cotas, o maior impedimento para as organizações contratarem pessoas com Deficiência é a dificuldade de tornar as estações de trabalho acessiveis para pessoas com todos os tipos de Deficiência."

"Acessibilidade ruim no trajeto até o trabalho" "Locomoção dentro dos espaços, conlocalização com fontes pequenas, não há informações em Braile"

"Para o baixa visão é mais fácil conseguir emprego do que para um cego. Acho baixa visão ainda consegue. Há preconceito, abrem vagas para deficientes mas não pegam o deficiente visual, preferem outros tipos de deficiência" "O deficiente visual monocular é um dos mais discriminados pela familia, pelo mercado de trabalho e pela sociedade em geral. As pessoas não entendem as dificuldades que só quem
tem essa deficiência passa no dia a dia para conseguir trabalho e direitos constituidos por lei as empresas não respeitam a lei. A sociedade faz pouco caso do problema, como se fosse fácil enxergam apenas com um olho."

"Não há impedimentos porém os empregados dificultam a inserção" "Não existe impedimento. É preciso força de vontade a paciência com as situações. Quem quer quiser ter empregos "subalternos" precisa se dedicar e estudar."

"Falta de oportunidade, não tem onde recorrer, poucas opções e pouca capacitação profissional" "O que dificulta é a falta de estudo"

"A familia impedir de trabalhar" "Bloqueio da familia em colocar o cego na sociedade"

"A pensão a aposentadoria impedem, eu recebo o beneficio e queria trabalhar sem carteira assinada para não perder o benefício, mas não consigo." "Receber o auxilio doença por que te dá medo de trocar o certo pelo incerto"
Na comparação das respostas em função do sexo, não foram encontradas diferenças estatisticamente significativas para os motivos de insatisfação no trabalho. Já para as dificuldades de inserção laboral, apenas na categoria "Falta de acessibilidade na cidade ou empresa" houve diferenças com significância estatistica, sendo que as mulheres endossaram mais essa categoria quando comparadas aos homens. $\mathrm{Na}$ sequência, realizou-se a comparação em função do nível de escolaridade, não sendo encontradas diferenças em função desta variável para nenhuma das categorias de respostas das duas perguntas. Em relação à comparação por tipo de deficiência, houve diferenciação estatisticamente significativa entre os grupos, sendo que a Tabela 3 apresenta tais resultados. 
TABELA 3 - Análise de variância e Tukey para insatisfação e dificuldades de inserção em função do tipo de deficiência.

\section{Insatisfação no trabalho}

\begin{tabular}{|c|c|c|c|c|c|c|}
\hline \multirow{2}{*}{ Categoria } & \multirow{2}{*}{ gl } & \multirow{2}{*}{$\mathbf{F}$} & \multirow{2}{*}{$p$} & \multirow{2}{*}{ Tipo de deficiência } & \multicolumn{2}{|c|}{ Subconjuntos } \\
\hline & & & & & 1 & 2 \\
\hline \multirow{4}{*}{$\begin{array}{c}\text { Conflitos } \\
\text { organizacionais }\end{array}$} & 3 & 2,919 & 0,04 & Baixa visão adquirida & 0,17 & \\
\hline & & & & Cegueira congênita & 0,22 & \\
\hline & & & & Baixa visão congênita & 0,29 & \\
\hline & & & & Cegueira adquirida & 0,64 & \\
\hline \multicolumn{7}{|c|}{ Dificuldades de inserção laboral } \\
\hline \multirow{4}{*}{ Preconceito } & 3 &, 213 & 0,00 & Cegueira adquirida & 0,25 & \\
\hline & & & & Baixa visão adquirida & 0,28 & \\
\hline & & & & Baixa visão congênita & 0,41 & 0,41 \\
\hline & & & & Cegueira congênita & & 0,65 \\
\hline \multirow{4}{*}{$\begin{array}{c}\text { Falta de aceitação } \\
\text { própria }\end{array}$} & 3 & 2,599 & 0,05 & Baixa visão adquirida & 0,00 & \\
\hline & & & & Cegueira adquirida & 0,05 & 0,05 \\
\hline & & & & Baixa visão congênita & 0,05 & 0,05 \\
\hline & & & & Cegueira congênita & & 0,17 \\
\hline \multirow{4}{*}{$\begin{array}{l}\text { Ineficiência da Lei } \\
\text { de Cotas }\end{array}$} & 3 & 3.750 & 0,01 & Cegueira adquirida & 0,00 & \\
\hline & & & & Baixa visão congênita & 0,00 & \\
\hline & & & & Baixa visão adquirida & 0,03 & 0,03 \\
\hline & & & & Cegueira congênita & & 0,13 \\
\hline
\end{tabular}

Observa-se que em relação aos motivos de insatisfação no trabalho, apenas a categoria "Conflitos organizacionais" obteve significância estatística, porém, sem diferenciação entre os grupos. Os resultados indicam que pessoas com cegueira congênita tendem a ter mais insatisfações no ambiente laboral em função das relações estabelecidas ou por questões que envolvem o planejamento de carreira. Em relação aos motivos de dificuldade para inserção laboral, os resultados foram significativos estatisticamente apenas para três categorias com formação de subconjuntos em todas. Na categoria "preconceito" e "ineficiência da Lei de Cotas" foram identificados fatores mais limitantes para pessoas com cegueira congênita do que para aquelas que adquiriram a cegueira ao longo da vida. $O$ grupo de pessoas com cegueira congênita também endossou mais a categoria "falta de aceitação própria" do que os demais, diferenciandose de pessoas com baixa visão adquirida.

\section{Discussão}

O presente estudo teve como objetivo verificar a percepção de satisfação no trabalho, insatisfações e dificuldades de inserção laboral de pessoas com deficiência visual, bem como, analisar diferenças em função do sexo, tipo de deficiência e nivel de escolaridade. Tal estudo justifica-se pela necessidade de avançar na discussão acerca da inserção de pessoas com 
deficiência no mercado de trabalho (Hanif, Peters, McDougall, \& Lindsay, 2017; Ribeiro \& Ribeiro, 2012; Ribeiro et al., 2014), e, especificamente, pela importância em buscar compreender como esse processo é percebido por pessoas com deficiência visual, grupo de maior prevalência entre as deficiências no Brasil (IBGE, 2011).

Ao analisar o grau de satisfação entre os participantes laboralmente ativos, percebe-se o predomínio daqueles que informaram estar satisfeitos com o trabalho. Tal resultado pode ser um indicativo positivo de que a inclusão está ocorrendo de maneira satisfatória para a maioria dos participantes. Todavia, cabe lembrar que da amostra total, apenas 55 participantes trabalhavam no momento da pesquisa indicando que muitas barreiras ainda existem para que haja oportunidades de trabalho para todos. Neste sentido, é necessário o desenvolvimento de estratégias que possam permitir o acesso ao trabalho, rompendo com o estigma vigente no qual as pessoas com deficiência não estariam aptas a desempenhar funções produtivas no mercado de trabalho (Ribeiro \& Ribeiro, 2012).

Em relação aos motivos de insatisfação com o trabalho, as maiores frequências foram encontradas para as categorias "conflitos organizacionais" e "falta de acessibilidade". Tal fato, em primeira instância, reflete 0 descumprimento da Lei Brasileira de Inclusão da Pessoa com Deficiência que determina a adequação dos espaços físicos para pleno acesso independentemente do tipo de deficiência. Especificamente ao pensar a acessibilidade para pessoas com deficiência visual, há maior necessidade de adaptações estruturais (pisos táteis, informações em braile, investimento em tecnologias assistiva, disposição de móveis que permitam o uso de bengala, entre outros). Assim, percebe-se que os espaços - planejados sob a ótica de pessoas videntes - desfavorecem e autonomia da pessoa com deficiência visual sendo de fundamental importância a adequação e o uso de princípios como o desenho universal na superação de barreiras físicas (Governo do Estado de São Paulo, 2010).
Em termos de conflitos organizacionais, os discursos dos participantes refletem a falta de habilidade da sociedade em estabelecer relações com pessoas com deficiência. Assim, as falas que se referem à falta de reconhecimento profissional, bem como, da ausência de um plano de carreira estruturado indicam que a inclusão tem seguido o apontado por Ribeiro e Ribeiro (2012) no qual a pessoa com deficiência, embora esteja dentro da organização, continua tendo um papel de tutelado ou vista sob a ótica de incapaz. Especificamente sobre o plano de carreira, o nivel de satisfação com o trabalho aumenta em pessoas com deficiência na medida em que percebem que a organização tem um plano claro de gestão e investe na qualificação dos funcionários (Assunção et al., 2015). Assim, é importante que os gestores e equipe de recursos humanos atentem-se para o desenvolvimento profissional do público, por meio de treinamentos que envolvam todos os agentes dos processos organizacionais, facilitando o estabelecimento de relações positivas entre pessoas com e sem deficiências

No que concerne às principais dificuldades de inserção no mercado de trabalho, os achados expõem um problema social que parece estar longe de ser resolvido. O principal aspecto identificado pelos participantes como limitante para inserção laboral foi o preconceito, seguido do desconhecimento social sobre a deficiência. As falas indicam que na percepção de pessoas com deficiência visual, esses são entendidos pela sociedade como incapazes, sem utilidade ou não passivel de credibilidade para desempenhar funções. Nesta direção, parece estar vigente ainda um campo de trabalho sem espaço para a diversidade, pautado na normatividade (Ribeiro \& Ribeiro, 2008)

Além disso, aliado ao desprazer em exercer a função, há pessoas que em suas falas denunciam uma prática de inclusão ilusória, como no caso de pessoas que relatam estar no emprego, porém, sem uma função real. Embora neste estudo a frequência de respostas dessa categoria tenha sido baixa, tal prática não é incomum e reforça a ideia de tutela da pessoa com deficiência (Ribeiro \& Ribeiro, 2008) conferindo-lhe o rótulo de incapaz 
no sistema de produção. Neste sentido, o fato dos empregadores estarem contratando pessoas com deficiência, nem sempre significa a percepção de igualdade entre os demais colaboradores (Ribeiro \& Ribeiro, 2012), uma vez que, essa inserção pode ocorrer exclusivamente a fim de cumprir a Lei de Cotas sem que a pessoa contratada desempenhe uma função real, exercendo um trabalho com sentido e correspondente as suas reais competências (Assunção et al., 2015).

Um aspecto que merece destaque é em relação à falta de aceitação própria e da percepção da deficiência como maior impedimento para inserção no trabalho. Os resultados indicam que há uma internalização de crenças limitantes por parte de algumas pessoas em relação às suas capacidades e competências. Ao analisar esse resultado por tipo de deficiência, as pessoas com cegueira congênita endossaram mais essa categoria quando comparada com as demais. Tal dado pode ser um indicativo de que as pessoas que nascem com cegueira possivelmente estejam sendo mais superprotegidas ou limitadas, não tendo grandes incentivos para que desenvolvam a autonomia e crenças mais positivas em relação a si. Neste sentido, torna-se importante desenvolver estratégias de promoção de crenças positivas, autoconhecimento de habilidades, autonomia e autoestima para lidar com as questões cotidianas, superando o preconceito internalizado por meio de consciência crítica sobre a própria deficiência (Simões, 2016).

Os resultados observados nas falas dos participantes na categoria "deficiência" indicaram que a inserção no mercado de trabalho é percebida como mais fácil para pessoas com baixa visão, sendo tal tipo preferido no momento da contratação. Surge também o relato de dificuldades de um subgrupo pouco discutido na literatura, referente às pessoas com visão monocular, bem como, das vagas para pessoas com deficiência serem preenchidas por pessoas com outros tipos de deficiência que não a visual. Os discursos confirmam os apontamentos de outros autores (Lima et al., 2010; Toldrá, 2009; Veltrone \& Almeida, 2010; Violante \& Leite, 2011) de que a contratação por meio da Lei de Cotas tem favorecido pessoas com deficiência nas quais não haja necessidade de grandes adaptações no espaço físico das empresas e instituições. Outro aspecto que envolve questões legais é em relação aos discursos de que o Benefício de Prestação Continuada (BPC) pode ser perdido por estabelecer vínculo empregatício sem posterior recuperação em caso de desemprego, confirmando a carência de informações da população em relação aos seus direitos (Cardoso \& Kern, 2016). A Lei assegura que caso a pessoa perca o emprego, automaticamente volte a receber o benefício, sendo necessárias ações de conscientização sobre esse direito.

Por fim, a comparação entre médias em dificuldades para inserção laboral apresentou resultados significativos com maiores pontuações para pessoas com deficiência visual do tipo congênita. Tais resultados dão indicativos de que essa população pode estar sendo limitada em seu desenvolvimento e inserção social em função de ter nascido com cegueira. Assim, torna-se importante que as familia e instituições estimulem o mais precocemente possivel o desenvolvimento desses aspectos para que a pessoa com deficiência visual congênita enfrente menos prejuizos de inserção social e tenha menos percepções negativas no campo laboral tal como os achados deste estudo sugerem. Sabe-se que a pessoa com cegueira congênita apresenta diferenças em relação à pessoa que adquiriu a deficiência ao longo da vida (Gonzáles, 2007), tais como, limitação da criação da imagem estética e corporal (Almeida \& Araújo, 2013), prejuizos no desenvolvimento de conceitos e constituição subjetiva (Cunha \& Enumo, 2003) e, consequentemente, nos aspectos emocionais (Amarilian, 2007) e habilidades sociais (Ferreira \& Del-Prette, 2013).

Pretendeu-se com este artigo verificar percepções de insatisfação no trabalho e barreiras para inclusão laboral de pessoas com deficiência visual sob a ótica desses. Os resultados indicaram que a inclusão ainda não tem se consolidado como uma prática eficaz e de acordo com os principios legais. As barreiras ambientais e atitudinais parecem ser os maiores entraves para a inserção 
e a permanência desse grupo no mercado de trabalho. Além disso, pessoas com deficiência do tipo congênita apresentaram maiores indices de insatisfação e de percepções negativas de inclusão, indicando que o tipo de deficiência acaba gerarando diferenças entre o público e reafirmando a necessidade de se pensar estratégias de superação das barreiras de acordo com as especificidades de cada grupo (Amarilian, 2007).

O estudo não tem por objetivo esgotar as discussões sobre a temática, ao contrário, frente às carências de investigações desta natureza, o intuito é contribuir com o debate iniciado por outros pesquisadores e estimular que outras pesquisas sejam realizadas. Neste sentido, é preciso considerar as limitações do presente estudo para que em futuras investigações sejam superadas. Em termos amostrais seria pertinente um maior equilibrio entre as regiões geopolíticas da federação para verificar possiveis influências regionais na inclusão laboral. Além disso, sugerese que sejam realizados estudos também com a participação da família e equipe de recursos humanos de empresas e instituições no intuito de identificar a participação ou interferências desses no nivel de satisfação com o trabalho e na inserção laboral.

Assim, acredita-se que apesar das limitações, os resultados deste estudo podem colaborar para melhor compreensão dos aspectos que são percebidos como limitantes para inclusão, bem como, quais atitudes geram mais insatisfações no ambiente laboral. Tais informações são úteis para todos aqueles que lidam com as questões de trabalho de pessoas com deficiência visual, tais como, gestores de empresas e instituições, psicólogos, profissionais de recursos humanos, orientadores profissionais e de carreira e educadores em niveis de ensino técnico profissionalizante e superior. Além desses, esse é um assunto que deveria ser de interesse da comunidade em geral, uma vez que a construção de uma sociedade justa e igualitária depende da conscientização de todos os setores sociais.

\section{Referências}

Almeida, T. S., \& Araujo, F. V. (2013). Diferenças experienciais entre pessoas com cegueira congênita e adquirida: Uma breve apreciação. Revista Interfaces: Saúde, Humanas e Tecnologia, 1(2), 1-21. (DOI INEXISTENTE)

Amiralian, M. L. T. M. (2007). A construção do eu de crianças cegas congênitas. Natureza humana, 9(1), 129-153. (DOI INEXISTENTE)

Andrade, A., Silva, I. S., \& Veloso, A. (2017). Integração profissional de pessoas com deficiência visual: Das práticas organizacionais às atitudes individuais. Revista Psicologia: Organizações e Trabalho, 17(2), 8088. doi: 10.17652/rpot/2017.2.12687

Assunção, R. V., Carvalho-Freitas, M. N. D., \& Oliveira, M. S. D. (2015). Satisfação no trabalho e oportunidades de desenvolvimento da carreira entre profissionais com deficiência. Revista Psicologia Organizações e Trabalho, 15(4), 340-351. doi: 10.17652/ rpot/2015.4.556

Bacelo, A. L. A. (2012). A integração de pessoas cegas no mercado de trabalho em Portugal (Dissertação de mestrado). Universidade de Aveiro: Portugal. (DOI INEXISTENTE)

Cardoso, L. K., \& Kern, C. (2016). Capacitação da pessoa com deficiência intelectual ao mercado de trabalho numa APAE do Sul de Santa Catarina. Revista de Ciências Humanas, 50(2), 437-458. doi: 10.5007/2178-4582.2016v5on2p437

Cunha, A. C. B., \& Enumo, S. R. F. (2003). Desenvolvimento de criança com deficiência visual (DV) e interacção mãe-criança: algumas considerações. Psicologia, Saúde \& Doença, 4(1), 33-46. (DOI INEXISTENTE)

Decreto $n^{\circ} 6.949$ de 25 de agosto de 2009. (2009). Promulga a Convenção Internacional sobre os Direitos das Pessoas com Deficiência e seu Protocolo Facultativo, assinados em Nova York, em 30 de março de 2007. Brasilia, 2009. (DOI INEXISTENTE)

Dipboye, R., \& Colella, A. (Orgs.). (2005). Discrimination at work: The psychological and organizational bases. Mahwah, New Jersey: Lawrence Erlbaum Associates. (DOI INEXISTENTE)

Ferreira, B. C., \& Del-Prette, Z. A. P. (2013). Programa de Expressividade Facial de Emoções e Habilidades Sociais de crianças deficientes visuais e videntes. Psicologia: Reflexão e Critica, 26(2), 327-338. (DOI INEXISTENTE)

Garcia, V. G., \& Maia, A. G. (2014). Caracteristicas da participação das pessoas com deficiência e/ou limitação funcional no mercado de trabalho brasileiro. Revista Brasileira de Estudos de População, 31(2), 395-418. (DOI INEXISTENTE)

González, E. (2007). Necessidades educacionais especificas: intervenção psicoeducacional. Porto Alegre: Artmed Editora. (DOI INEXISTENTE) 
Governo do Estado de São Paulo, Secretaria de Estado da Habitação \& Secretaria de Estado dos Direitos da Pessoa com Deficiência. (2010). Desenho Universal: habitação de interesse social. (DOI INEXISTENTE)

Hanif, S., Peters, H., McDougall, C., \& Lindsay, S. (2017). A systematic review of vocational interventions for youth with physical disabilities. In Factors in Studying Employment for Persons with Disability: How the Picture Can Change (pp. 181-202). Emerald Publishing Limited. (DOI INEXISTENTE)

Hashim, H., Ishak, N. A., \& Hilmi, Z. A. G. (2017). Job Embeddedness and Organizational Climate. Asian Journal of Quality of Life, 2(6), 31-42. doi: 10.21834/ajqol.v2i6.44

Instituto Brasileiro de Geografia e Estatísticas - IBGE (2010). Censo Demográfico 2010: Caracteristicas gerais da população, religião e pessoas com deficiência Ministério do Planejamento, Orçamento e Gestão.

\section{(DOI INEXISTENTE)}

Lei no 8.213 de 24 de julho de 1991. (1991). Dispõe sobre os Planos de Benefícios da Previdência Social e da outras providências. Brasília, 1991. (DOI INEXISTENTE)

Lei $n^{\circ} 13.146$ de 6 de julho de 2015. (2015). Institui a Lei Brasileira de Inclusão da Pessoa com Deficiência (Estatuto da Pessoa com Deficiência). Brasilia, 2015.

Lima, J. P., da Silva, T. B., \& Galvão, E. C. F. (2010). A percepção dos empregadores sobre a admissão de trabalhadores com Sindrome de Down. Health Scientist Institute, 28(1), 17-20. (DOI INEXISTENTE)

Moraes, R. (1999). Análise de conteúdo. Revista Educação, 22(37), 7-32. (DOI INEXISTENTE)

Pinheiro, L. R. S., \& Dellatorre, R. (2015). Desafios da Inclusão de Pessoas com Deficiência no Mercado de Trabalho: Um Estudo sobre a Percepção dos Envolvidos. Perspectiva, 39(148), 95-109. (DOI INEXISTENTE)

Ribeiro, A. P., Batista, D. F., Prado, J. M., Vieira, K. E., \& Carvalho, R. L. (2014). Cenário da inserção de pessoas com deficiência no mercado de trabalho: revisão sistemática Revista da Universidade Vale do Rio Verde, 12(2), 268-276. doi: 10.5892/ruvrd.v12i2.1441.

Ribeiro, M. A., \& Ribeiro, F. (2008). Gestão organizacional da diversidade: Um estudo de caso de um programa de inclusão de pessoas com deficiência. In M. N. Carvalho-Freitas, \& A. L. Marques (Orgs.), O trabalho e as pessoas com deficiência: Pesquisas, práticas e instrumentos de diagnóstico (pp. 122-141). Curitiba: Juruá. (DOI INEXISTENTE)

Ribeiro, M. A., \& Ribeiro, F. (2012). O desenvolvimento da carreira de pessoas com deficiência em empresas: dificuldades e perspectivas. Gerais: Revista Interinstitucional de Psicologia, 5(1), 127-145. (DOI INEXISTENTE)

Simões, M. C. D. (2016). Autonomia, Formação, Deficiência Visual e Ledores. Journal of Research in Special Educational Needs, 16(S1), 255-258. doi: 10.1111/14713802.12146
Toldrá, R. C. (2009). Políticas afirmativas: opinião das pessoas com deficiência acerca da legislação de reserva de vagas no mercado de trabalho. Revista de Terapia Ocupacional da Universidade de São Paulo, 20(2), 110-117. doi: 10.11606/issn.2238-6149.v20i2p110-117

Veltrone, A. A., \& Almeida, M. A. (2010). Perfil da pessoa com deficiência no mercado de trabalho na cidade de São Carlos-SP. Revista Educação Especial, 23(36), 73-90. (DOI INEXISTENTE)

Violante, R. R., \& Leite, L. P. (2011). A empregabilidade das pessoas com deficiência: uma análise da inclusão social no mercado de trabalho do município de Bauru, SP. Cadernos de Psicologia Social do TrabaIho, 14(1), 73-91. (DOI INEXISTENTE)

\section{Endereço para correspondência:}

Leonardo de Oliveira Barros (Waldemar César da Silveira, 105 - Jardim Cura D'ars, Campinas - SP, 13045-510); (18) 981871994; leonardobarros_lob@hotmail.com).

Autor I

Nome: Leonardo de Oliveira Barros

Titulação Acadêmica: Doutor em Psicologia

Afiliação Institucional: Universidade São Francisco (USF).

\section{Autor II}

Nome: Rodolfo Augusto Matteo Ambiel

Titulação Acadêmica: Doutor em Psicologia

Afiliação Institucional: Universidade São Francisco (USF). 